\title{
O extrativismo da fava d'anta (Dimorphandra mollis Benth.) na região do Norte de Minas Gerais
}

\author{
NUNES, J.D.*; NERY, P.S.; FIGUEIREDO, L.S.; COSTA, C.A. ; MARTINS, E.R. \\ Instituto de Ciências Agrárias (ICA)UFMG- Campus Regional de Montes Claros, Avenida Universitária, 1.000 - \\ Bairro Universitário, CEP: 34690-000, Montes Claros-Brasil *josefinadorotea.nunes@bol.com.br
}

\begin{abstract}
RESUMO: A exploração desenfreada dos ecossistemas tropicais, principalmente o Cerrado, tem provocado uma redução nos indivíduos de inúmeras espécies medicinais, levando prejuízos para toda a população. A falta de informações sobre o extrativismo tem dificultado o uso de estratégias eficazes de manejo e conservação das espécies do cerrado. A fava-d'anta é uma dessas espécies nativas que possuem potencial econômico, principalmente devido à rutina, que é usada na fabricação de fármacos e de cosméticos. O objetivo deste estudo foi analisar os aspectos da atividade de coleta da fava-d'anta pelos coletores e comerciantes. Realizou-se entrevista estruturada com 61 extrativistas, sendo 44 coletores e 17 comerciantes em oito municípios do Norte de Minas Gerais. Constatou-se que a maioria dos entrevistados são homens casados, analfabetos ou com a primeira etapa do ensino fundamental. A coleta da fava-d'anta, apesar de pouco rentável, é uma alternativa para os coletores, sendo a renda inferior à dos comerciantes que já estão nesta atividade de compra da fava-d'anta há mais de 10 anos. A faixa etária de adulto e adulto/idoso são as mais representativas. Aépoca de maior produção ocorre entre os meses de abril a julho, a bienalidade da produção leva à mudança do local de extração. Observou-se 0 auxílio de toda a família na atividade. Utiliza-se como instrumento de coleta o podão, a foice, facões e outras ferramentas que danificam as árvores. A maior dificuldade para os coletores é a secagem e, para os comerciantes, a venda. O plantio ou a produção de mudas não tem sido prática habitual dos entrevistados.
\end{abstract}

Palavras-chave: extrativismo, educação ambiental, conservação, planta medicinal

\begin{abstract}
Harvest of "fava-d'anta" (Dimorphandra mollis Benth.) in the northern region of Minas Gerais State, Brazil. The uncontrolled exploitation of tropical ecosystems, especially Cerrado, has caused a reduction in individuals of many medicinal plant species, causing damage to the entire population. The lack of information about extraction has hindered the use of effective strategies for management and conservation of Cerrado species. "Fava-d'anta" is one of those native species that have economic potential, largely due to rutin, which is used in the preparation of drugs and cosmetics. The aim of this study was to analyze aspects of the activity of "favad'anta" harvest by harvesters and traders. We conducted a structured interview with 61 gatherers, 44 harvesters and 17 traders in eight counties in northern Minas Gerais State, Brazil. Most of them are men who are married and illiterate or had just studied the first stage of basic education. Although little profitable, "fava-d'anta" harvest is an alternative for harvesters, who obtain an income lower than that of traders, who in turn have been trading "fava-d'anta" for more than 10 years. The age range of adults and aged/adults are most representative. The period of greatest production is between April and July, and the 2 year production cycle leads to a change in the extraction site. The whole family helps in the extraction. The instruments used for harvest are trimmers, sickles, machetes and other tools that damage the trees. The greatest difficulty for collectors is seed drying and for traders, selling. The planting or the production of seedlings has not been the usual practice of interviewees.
\end{abstract}

Key words: extraction, environmental education, conservation, medicinal plant

Recebido para publicação em 12/05/2011

Aceito para publicação em 16/03/2012

Rev. Bras. PI. Med., Botucatu, v.14, n.2, p.370-375, 2012. 


\section{INTRODUÇÃO}

O extrativismo de plantas medicinais no Cerrado é uma forma de sobrevivência para algumas comunidades que encontram dificuldades para o plantio de culturas de subsistência devido à escassez de água, a baixa fertilidade do solo e a falta dos recursos para investimento social na área. Observou-se que famílias inteiras dependem de recursos gerados do extrativismo de plantas com propriedades medicinais do domínio Cerrado (Gomes \& Gomes, 2000).

Entre as espécies do Cerrado com grande potencial de exploração econômica destaca-se a favad'anta, Dimorphandra mollis Benth., que é árvore com legumes carnosos, ricos em rutina, quercetina e ramnose. Estes flavonóides e o açúcar ramnose são utilizados pela indústria farmacêutica em grande escala, tendo maior importância a rutina. Gomes \& Gomes (2000) relataram que $50 \%$ da produção mundial de rutina é proveniente da fava-d'anta, sendo que apenas $60 \%$ da demanda mundial tem sido atendida, justificando a expansão do mercado e a preocupação com a integridade e preservação da espécie, por constituir a maior fonte desse princípio ativo.

Os estados do Maranhão, Piauí e Minas Gerais, são os maiores fornecedores das favas, e Minas Gerais é o primeiro estado a fornecer as favas, a partir da segunda quinzena do mês de abril (Gomes, 1998).

Devido a importância econômica a fava-d'anta vem sofrendo extrativismo predatório, os frutos são coletados antes de alcançarem o ponto de maturação, o que prejudica a sobrevivência da espécie a longo prazo (Mendes de Paula et al., 2007). Outra questão importante é que a retirada das vagens das pontas dos galhos é realizada com as mãos ou com instrumentos rústicos onde, muitas vezes, os galhos são quebrados para facilitar a coleta e assim prejudicando a produção da planta no ano seguinte (Gomes, 1998).

Segundo Gomes \& Gomes (2000), a coleta da fava é uma alternativa de renda para os trabalhadores rurais e para as famílias no Norte de Minas Gerais; no entanto, a maior parte da renda gerada pelo extrativismo da espécie não tem auxiliado na melhoria de vida dessa população.

Nesse contexto, trabalhou-se com o objetivo de levantar, junto a comunidades que coletam a favad'anta na região do Norte de Minas Gerais, qual a situação atual da exploração da espécie, a importância do extrativismo para as famílias de coletores e comerciantes; a percepção da comunidade sobre os danos do extrativismo e aspectos do manejo e conservação.

\section{MATERIAL E MÉTODO}

O trabalho foi realizado na região do Norte de Minas Gerais, nos municípios de Brasília de Minas, Coração de Jesus, Japonvar, Francisco Dumont, Luislândia, Jequitaí, São Francisco e Montes Claros.
Segundo o IBGE a mesorregião Norte de Minas Gerais é composta por 89 municípios, sendo a amostragem desse estudo de aproximadamente $9 \%$. Os municípios foram escolhidos aleatoriamente dentre aqueles que praticam o extrativismo da fava-d'anta.

Utilizou-se o método de questionamento proposto por Albuquerque et al. (2008), sendo utilizada a entrevista estruturada por meio de questionário. $O$ questionário avaliou grau de instrução, renda familiar antes e após a coleta, como aprendeu a coletar, se coleta sempre no mesmo local, qual é o período em que a coleta é realizada, em qual fase de desenvolvimento se coleta, qual a quantidade em $\mathrm{Kg}$ da safra de 2009, para quem repassa a coleta, quais as dificuldades na comercialização, se sabem qual o destino do produto e qual a experiência com a produção de mudas ou plantio da espécie.

Foi utilizado o termo "coletores" para designar os pequenos produtores rurais, que, na safra da favad'anta, coletam frutos para complementar os gastos domésticos, e o termo "comerciantes", para os produtores rurais ou praticantes de atividades comerciais diversas. Esses comerciantes, geralmente, estão vinculados a atividades como loja, açougue, padaria, entre outros, e revendem os frutos secos, aos atacadistas regionais, que não foram incluídos no presente estudo.

As visitas para a realização das entrevistas foram precedidas de contato com técnicos e lideranças de cada município com a finalidade de levantar informações sobre possíveis entrevistados na comunidade (nomes, telefones e endereços). Não se constatou nenhuma associação ou entidade que organiza os extrativistas na região pesquisada.

Verificou-se a disponibilidade de cada possível entrevistado em contribuir com o estudo por meio do termo de consentimento livre e esclarecido. A pesquisa foi aprovada pelo Comitê de Ética em Pesquisa da UFMG - COEP, sob o no ETIC 0293.0. 203.000-10.

\section{RESULTADO E DISCUSSÃO}

Realizaram-se 61 entrevistas, sendo $72 \%$ coletores e $28 \%$ comerciantes. Deste total, $64 \%$ dos coletores e $82 \%$ dos comerciantes eram do sexo masculino. As mulheres apesar de estarem em menor número desempenham papel importantíssimo, pois auxiliam o companheiro na coleta, na secagem, no ensacamento e na venda dos frutos. Somente na cidade de Francisco Dumont, constatou-se a maior presença da mulher como responsável principal na compra da fava-d'anta.

Entre os coletores, $32 \%$ pertencem à faixa etária de adulto/idoso ( 50 a 65 anos), $41 \%$ à faixa de adulto (35 a 49 anos) e $16 \%$ a de adultos jovens (18

Rev. Bras. Pl. Med., Botucatu, v.14, n.2, p.370-375, 2012. 
a 34 anos). Já os comerciantes $59 \%$ pertencem à faixa etária de adulto/idoso ( 50 a 65 anos), 35\% à faixa de adulto ( 35 a 49 anos) e $6 \%$ a de adultos jovens (18 a 34 anos). Constatou-se que os adultos jovens comerciantes são filhos que "herdaram" do pai a atividade de compra da fava-d'anta na região.

Entre os entrevistados, $70 \%$ dos coletores e $94 \%$ dos comerciantes são casados. Dos $16 \%$ de adultos jovens entre os coletores, $20 \%$ são solteiros, no entanto, entre os comerciantes apenas $6 \%$. Não foi relatado, por nenhum dos entrevistados, 0 casamento entre coletores e comerciantes.

Com relação à escolaridade (Figura 1), constatou-se que $41 \%$ dos coletores e $12 \%$ dos comerciantes são analfabetos. Entre aqueles que frequentaram a primeira etapa do ensino fundamental, tem-se, $41 \%$ dos coletore e $56 \%$ comerciantes. Notase que, entre os comerciantes, $13 \%$ frequentaram a segunda etapa do Ensino Fundamental e 19\% concluíram o Ensino Médio.

Foi observado que a principal atividade dos coletores é a de lavrador ou pequeno produtor rural. Já o comerciante possui propriedades rurais e urbanas (comércio local). Isto vai de acordo com Gomes (1998), que relata a atividade principal dos "atacadistas locais" como produtores rurais e urbanos, vinculados a algum tipo de comércio e que os coletores são trabalhadores rurais.

A época da coleta ocorre entre os meses de Maio a Julho, tendo o pico no mês de Junho. Isso corrobora os estudos de Pereira (2006), que relata que Minas Gerais é o primeiro estado a fornecer o produto, iniciando em Abril e estendendo-se até Julho. Os comerciantes não tem interesse nos frutos maduros. "Se estiver madura, com cheiro de banana, o pessoal da empresa não compra" (Entrevistado 1).

Entre os coletores, $72 \%$ não se preocupam em fazer a coleta em locais específicos, isto é, eles irão onde ocorrer a espécie. Já $100 \%$ dos comerciantes relataram que contratam os coletores para fazer a coleta das favas nos terrenos, mas também compram frutos vindas de outros locais. Foram registrados relatos de que alguns fazendeiros não deixam que se faça a coleta nas propriedades, pois não querem pessoas estranhas e há aqueles que cortaram todas as árvores da planta do terreno, devido à intoxicação em vacas, provocando aborto. Tal informação corrobora os estudos de Tokarnia et al. (2000), que admitem possíveis intoxicações nos bovinos devido à escassez ou à inexistência de pastagens durante o período de seca, levando ao consumo acidental da fava-d'anta.

Nota-se que $68 \%$ dos coletores e $59 \%$ dos comerciantes informaram que há mudança no local de coleta. Sendo um dos principais fatores para tal mudança a bienalidade da planta. Segundo os coletores, provavelmente, a coleta com quebra ou danos profundos nas árvores possam interferir também em tal mudança, pois as árvores danificadas dificilmente produzem no ano seguinte. Conforme relato de Caldeira Júnior et al. (2008), esse comportamento foi observado nessa espécie em cinco comunidades ou municípios no norte do Estado de Minas Gerais. Já para os coletores, essa mudança é devido ao desmatamento, às queimadas, à monocultura e à retirada de forma incorreta dos frutos, com a quebra de galhos, causando danos às plantas e ao ambiente onde se encontram: "O desmatamento,

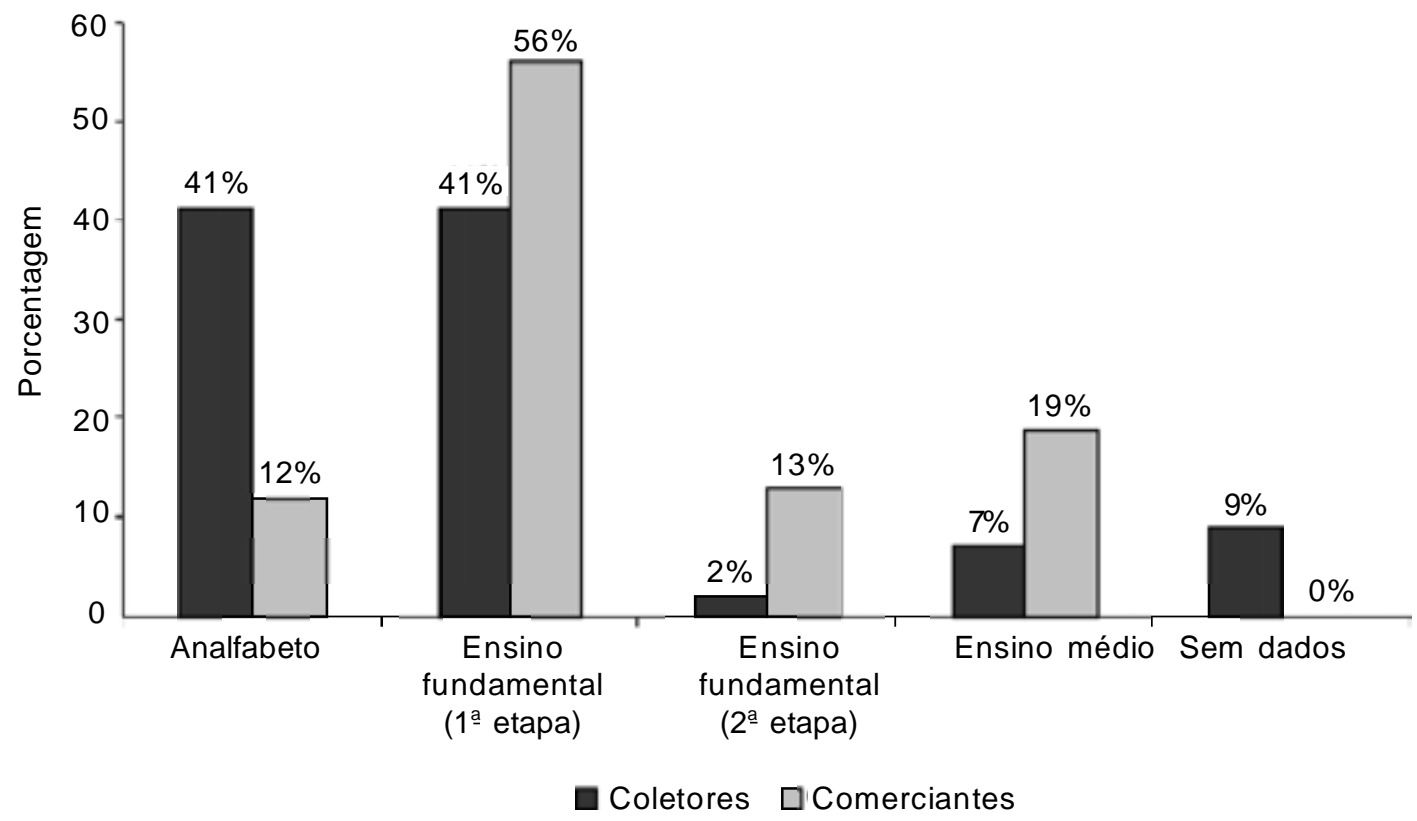

FIGURA 1. Escolaridade dos coletores e comerciantes envolvidos com o extrativismo de fava-d'anta (Dimorphandra mollis Benth.), entrevistados no Norte de Minas Gerais. 
as plantações de eucalipto e as queimadas é que estão acabando com as plantas todas do cerrado" (Entrevistado 2); " O desmatamento há mais de 10 anos destruiu tudo, tem muitas minas de água que secaram" (Entrevistado 3).

Observou-se que para $68 \%$ dos coletores e $71 \%$ dos comerciantes, é comum que outros membros da família auxiliem na coleta. Entre os comerciantes é mais comum a ajuda somente dos filhos e, no caso dos coletores, é frequente a ajuda da esposa e de filhos, que vai de acordo com Macedo et al. (2004), que relatam que a coleta é feita por famílias inteiras de trabalhadores rurais.

Constatou-se que a secagem é o processo considerado como a maior dificuldade no extrativismo da espécie, tanto na visão dos coletores representando $61 \%$ do total, quanto na dos comerciantes representando $47 \%$ do total (Figura 2).

Segundo Gomes \& Gomes (2000), a secagem da fava-d'anta leva de 8 a 12 dias, com os frutos espalhados ao sol. Um entrevistado afirma: As favas não secam por igual e a gente passa vários dias tendo que mudá-las de posição. É muito trabalhoso (Entrevistado 4)". A coleta propriamente dita é a maior dificuldade na opinião de $43 \%$ dos coletores. Conforme Gomes \& Gomes (2000), os coletores buscam a fava a pé ou de bicicleta, percorrendo em torno de $15 \mathrm{~km}$ de distância da sua residência. A armazenagem, que, para $18 \%$ dos comerciantes, tem grande importância, somente 9\% dos coletores a citaram. A venda proporciona algumas dificuldades para ambos os grupos. "No ano de 2009 a indústria farmacêutica não comprou nada, está tudo no saco" (Entrevistado 5). Tal fato tem sido realidade na região, uma vez que nem sempre os compradores das empresas aparecem na região, causando incerteza, dificultando a organização dos trabalhadores e desvalorizando o produto. Assim, percebe-se desestímulo e falta de perspectivas entre os entrevistados quanto ao futuro da atividade.

Cerca de $48 \%$ dos coletores afirmaram que utilizam o podão como ferramenta para a coleta dos frutos da fava-d'anta e, $43 \%$ fazem o uso de ferramentas como a foice, o facão e o gancho. No entanto, percebeu-se que os podões dos coletores quase sempre estavam em excelente estado, indicando pouco uso.

A quebra de galhos ocorre, de acordo com os coletores, em $7 \%$ dos casos, e para os comerciantes, em 17\%. Alguns coletores alegaram que "o podão é muito pesado"(Entrevistado 6), o que está de acordo com o observado por Gomes \& Gomes (2000), que relatam que a "panha" das vagens é realizada com as mãos ou instrumentos rústicos, levando algumas vezes à quebra de galhos para facilitar a coleta. Alguns coletores e comerciantes informaram que atualmente tem se deixado um "cacho" (corimbo) das favas por árvore, e que a quebra

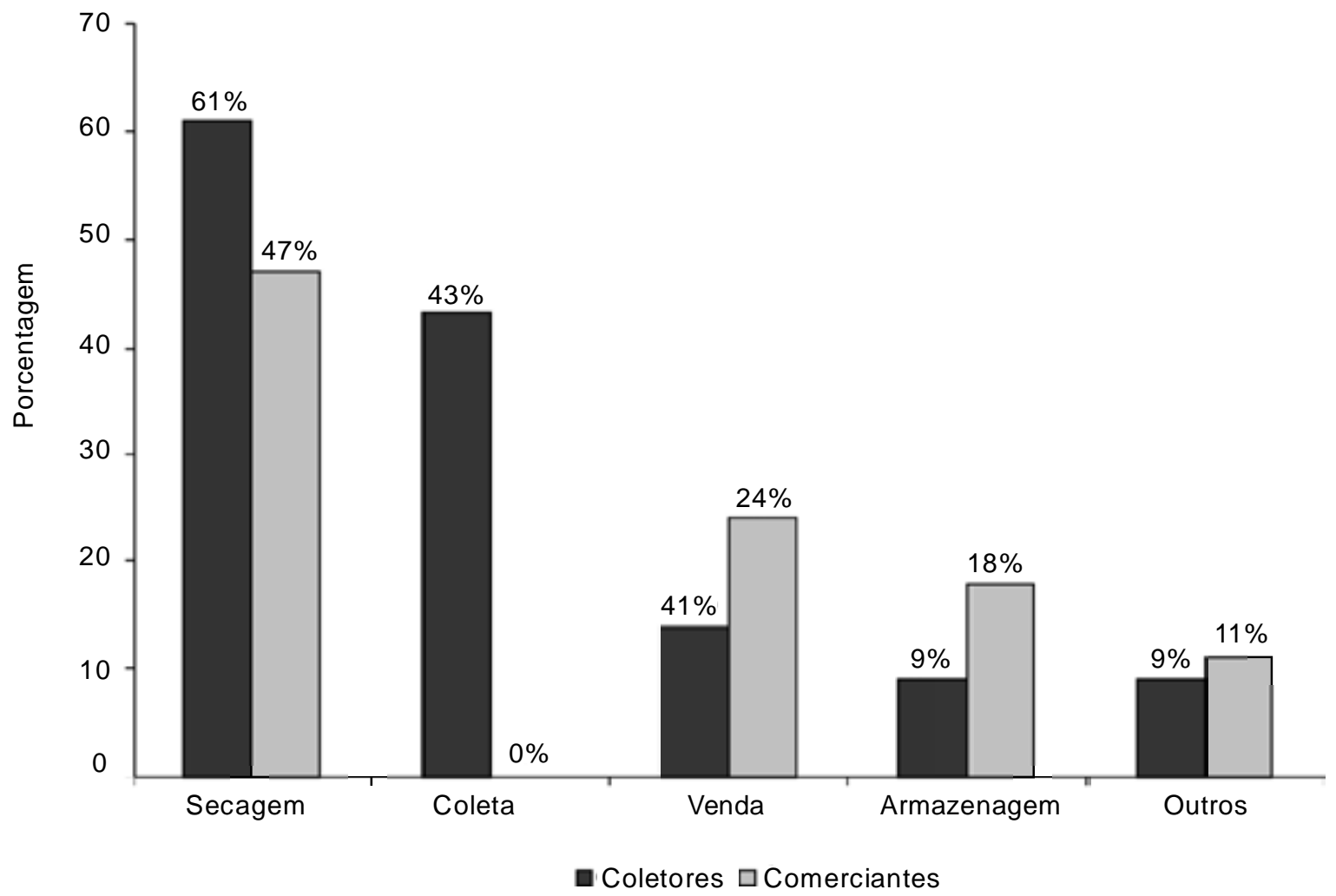

FIGURA 2. Dificuldades encontradas pelos coletores e comerciantes nos processos relacionados ao extrativismo da fava-d'anta (Dimorphandra mollis Benth.), no Norte de Minas Gerais. 
de galhos tem sido evitada por parte de todos, "se quebramos os galhos para pegar o fruto, no outro ano não dá fava" (Entrevistado 7), indicando que estão conscientes sobre os danos que a coleta desordenada pode provocar nas plantas e no seu próprio sustento. Entre os comerciantes, $71 \%$ informam que a coleta é feita com o uso do podão, embora reconheçam que muitos dos coletores fazem o uso de outras ferramentas. A contradição entre a informação dos coletores e comerciantes, sobre o uso do podão, reflete, em parte, a ausência de política eficaz que induza a produção sustentável da espécie. Assim, os comerciantes acreditam que os coletores utilizem o podão, mas esses, na maioria das vezes, não fazem uso do mesmo. Não foi observada, na região estudada, qualquer incentivo financeiro ou ação de educação ambiental para que os coletores utilizem o podão ou evitem danos às árvores. Apesar do destino dos frutos ser uma única empresa, não se detectou qualquer incentivo à redução de danos ou à conservação da espécie na área abrangida no estudo, à exceção da distribuição de podões, os quais não são usados frequentemente.

A espécie pesquisada pode estar ameaçada, pois foi possivel perceber que não existe preocupação por parte da maioria dos entrevistados na propagação da especie, uma vez que $93 \%$ dos coletores e $82 \%$ dos comerciantes nunca produziram mudas e $89 \%$ e $82 \%$, respectivamente, não tentaram fazer plantios ou adensamento de áreas naturais de ocorrência.

Gomes (1998) relata que nenhum dos entrevistados, sabiam ou tentaram produzir mudas de fava-d'anta. Vários extrativistas, entrevistados nesta pesquisa, alegaram não saber como fazer a semente germinar (quebrar a dormência da semente), além da falta de instruções para o plantio. Somente nas cidades de São Francisco e na Comunidade de Abóboras, em Montes Claros, alguns coletores (11\%) e comerciantes (18\%) estão plantando as mudas de fava-d'anta. No entanto, são iniciativas isoladas influenciadas por instituições que desenvolvem projetos locais. De acordo com Fernandes et al. (2008), é necessário o desenvolvimento de tecnologias de produção de mudas de fava-d'anta, visando o manejo sustentável para a conservação dessa espécie e geração de renda.

Durante as entrevistas, foram marcantes as diferenças na realidade social e econômica entre coletores e comerciantes. Entre os comerciantes, $62 \%$ estão na atividade de compra da fava-d'anta há mais de 10 anos, pois o retorno financeiro é mais vantajoso, como descrito por Gomes (1998), tendo o "atacadista local" renda bruta anual, em 1997, estimada em $R \$ 45.000,00$, além de estarem vinculados a algum tipo de comércio, como bares, pequenos restaurantes, lojas, dentre outros.

Dentre os coletores, $79 \%$ não ficam por muito tempo nessa atividade, pois eles usam a coleta como renda extra. Os coletores atuam como lavradores e, quando mulheres, empregadas domésticas, e na coleta de outros frutos do cerrado. Resultado este semelhante ao encontrado por Gomes \& Gomes (2000), que relataram que o ganho na coleta da fava-d'anta é pequeno ( $7 \%$ da renda anual) quando comparado com a coleta do pequi $(50 \%$ da renda anual), da mangaba, do caju e da semente de sucupira. Observou-se que a renda familiar total de $73 \%$ dos coletores é de até $R \$ 465,00$, salário mínimo vigente em 2009 (Brasil, 2009).

Os frutos são vendidos diretamente dos coletores para os comerciantes locais (98\%) e desses para os comerciantes regionais (88\%), até chegarem a grandes indústrias farmacêuticas.

Constou-se que os comerciantes compram a fava-d'anta verde por cerca de $\mathrm{R} \$ 0,40$ por $\mathrm{kg}$, e seca por $\mathrm{R} \$ 0,70$ por kg. $O$ valor que os comerciantes recebem dos "atacadistas regionais" ou das indústrias não foi relatado. A fava verde não é comprada pelas indústrias. Segundo Gomes (1998) e Gomes \& Gomes (2000), é comum alguns comerciantes trocarem $1 \mathrm{~kg}$ de alimentos, para cada $10 \mathrm{~kg}$ de fava verde, e, para os adolescentes, a troca ocorre por doces, por exemplo.

De acordo com Gomes \& Gomes (2000), ocorre grande desconhecimento, por parte da população e de instituições locais, sobre o destino dessa matéria-prima. Observou-se que os coletores, no geral, não sabem qual o uso ou destino da favad'anta, sendo que $25 \%$ deles têm informações superficiais sobre a fabricação de medicamentos.

\section{CONCLUSÃO}

O extrativismo da fava-d'anta constitui alternativa sócio-econômica para coletores e comerciantes, nas comunidades pesquisadas. Os dados sugerem que os procedimentos de coleta, em sua maioria danificam a espécie, e em apenas duas comunidades existe a preocupação em propagar a espécie. Portanto, existe a necessidade ações de extensão junto aos coletores e comerciantes visando orientá-los sobre boas práticas de coleta e, principalmente, ao plantio para que sejam minimizados os impactos negativos sobre a espécie e mantida a renda alternativa para os atores sociais envolvidos na cadeia produtiva.

\section{REFERÊNCIA}

ALBUQUERQUE, U.P.; LUCENA, R.F.P.; CUNHA, L.V.F.C. Métodos e técnicas na pesquisa Etnobotânica. 2.ed. Recife: Comunigraf, 2008. 322p. 
BRASIL. 2009. Congresso Nacional. Lei № 11.944, de 28 de maio de 2009. Dispõe sobre o salário mínimo a partir de 1 de fevereiro de 2009. DOU. Diário Oficial [da] República Federativa do Brasil. 29 mai.2009.

CALDEIRA JÚNIOR, C.F. et al. Fenologia da fava-d'anta (Dimorphandra mollis Benth.) no norte de Minas Gerais, Brasil. Revista Brasileira de Plantas Medicinais, v.10, n.4, p.18-28, 2008.

ESTADO DE MINAS GERAIS, Mesorregiões e microrregiões (IBGE). Atualizado em dezembro de 2010. Disponível em: http://www.mg.gov.br/governomg/ecp/ contents.do ? evento $=$ conteudo \&idConteudo $=69547$ $\& \operatorname{chPlc}=6$ 9547\&termos $=\mathrm{s} \& \mathrm{app}=$ governomg $\& \operatorname{tax}=$ $0 \& \operatorname{taxp}=5922$. Acesso em: 1/2/2012.

FERNANDES, L.A. et al. Níveis de nitrogênio, fósforo e potássio para a produção de mudas de fava d'anta (Dimorphandra mollis Benth.). Revista Brasileira de Plantas Medicinais, Botucatu, v.10, n.1, p.94-9, 2008.

GOMES, L.J. Extrativismo e comercialização da fava d'anta (Dimorphandra sp.): um estudo de caso na região de Cerrado de Minas Gerais. 1998. 158p.
Dissertação (Mestrado em Engenharia Florestal) Universidade Federal de Lavras, Lavras.

GOMES, L.J.; GOMES, M.A.O. Extrativismo e biodiversidade: o caso da fava-d'anta. Ciência Hoje, v.27, n.161, p.66-9, 2000. MACEDO, E.A.S. et al. Influência da época de colheita, procedimento de secagem e parte do fruto no teor de flavonóides em fava d'anta (Dimorphandra mollis Benth.). Revista Brasileira de Plantas Medicinais, v.7, n.1, p.1-5, 2004.

MENDES DE PAULA, T.O. et al. Influência do silicato no crescimento inicial e produção de flavonóides totais em Dimorphandra mollis Benth. Revista Brasileira de Biociências, v.5, n.S2, p.552-4, 2007.

PEREIRA, V.F. Avaliação da capacidade de produção em áreas de coleta de Dimorphandra mollis Benth. no norte de Minas. 2006. 20p. Trabalho de conclusão de curso (Bacharel em Agronomia) - Universidade Federal de Minas Gerais Instituto de Ciências Agrárias, Montes Claros. TOKARNIA, C.H.; DÖBEREINER, J.; VARGAS, P.V. Plantas Tóxicas do Brasil. 1.ed. Rio de Janeiro: Helianthus, 2000. 310p. 